\title{
O TABACO E A INFÂNCIA
}

A forma mais eficiente de vingança dos nativos americanos, em resposta à carnificina e à pilhagem de nossos antepassados europeus, foi ter Ihes apresentado o tabaco. Utilizado na América pré-colombiana para fins medicinais e religiosos, chegou à Europa na bagagem de Cristóvão Colombo, misturado a todas as curiosidades que pôde levar do Novo Mundo. Ironicamente, foi justamente um médico da corte do rei espanhol Felipe II que o popularizou: alardeou muitos dos ditos benefícios do seu uso como uma verdadeira panacéia! .

Desde então, o vício foi assimilado nas mais diversas culturas e transformou-se na segunda causa de morte no mundo. Mata cinco milhões de pessoas ao ano e, se nada for feito, esse genocídio anual dobrará até o ano de $2020^{2}$. Por sua causa são gastos cerca de 200 bilhões de dólares anualmente, sendo um terço disto em países pobres: em famílias de baixo poder econômico chega a comprometer $10 \%$ da renda mensal ${ }^{3}$. Isso se multiplica se considerarmos as mortes por causas respiratórias em filhos de fumantes e o abandono escolar decorrente da retirada sistemática das salas de aula de filhos de lavradores nas épocas de colheita do fumo².

Qual é o papel das crianças e adolescentes nesse contexto? O mais vulnerável possível. Sabe-se que mais de 90\% das pessoas adquirem esse vício até os 19 anos de idade. Esta é a fatia mais atraente do mercado para as indústrias do tabaco e, por isso, a criança e o adolescente são os principais objetos de estudo destas indústrias, há mais de 30 anos, como demonstra esta frase do vice-presidente da Philip Morris, em 1969: "Para o principiante, fumar um cigarro é um ato simbólico. Eu não sou mais o filhinho da mamãe, eu sou durão, sou um aventureiro, não sou quadrado... À medida que o simbolismo psicológico perde a força, o efeito farmacológico assume o comando para manter o hábito..." 3

Por todas essas questões, estudos como o de Guedes e seus colaboradores, intitulado "Uso de tabaco e perfil lipídicolipoprotéico plasmático em adolescentes", são tão importantes: precisamos também conhecer profundamente as causas e conseqüências do tabagismo nessa faixa etária, bem como as melhores estratégias de prevenção e combate. Mas cabem aqui algumas considerações: por que existem diferenças tão significativas entre a prevalência do tabagismo encontradas entre adolescentes, em torno de 15\%, e entre adultos, em torno de $25 \%^{2,3}$, se o vício é adquirido até a adolescência? Quando começamos a estudar prevenção das doenças crônicas na infância e na adolescência aqui em Florianópolis", andávamos "à paisana" entre os alunos das escolas para sentir o que se passava no seu imaginário. Ouvíamos comentários como "imagina se eu vou dizer para eles que eu fumo! Eles vão direto contar para a diretora ou para a minha mãe!" Será que realmente sabemos quantos fumam entre os nossos pequenos? Como medir o efeito do tabagismo passivo e do fumo no crescimento e no desenvolvimento, considerando que muitos experimentam o tabaco aos sete anos de idade? ?5, $^{5}$

Será que as técnicas que utilizamos para a prevenção e o combate ao tabagismo impedem que as crianças fumem? A sensação é que o marketing em prol do cigarro está anosluz a nossa frente ${ }^{7}$. Será que nós, que nos propomos a cuidar da saúde da nossa população, não deveríamos estudar porque essas estratégias são tão eficientes e mudar as nossas intervenções?

Ao considerarmos os desafios no combate e prevenção do tabagismo no Brasil, nos defrontamos com dois grandes problemas: o primeiro é que nós, médicos, não temos sido bons exemplos em relação ao fumo. Apesar da mudança do papel do médico na sociedade contemporânea, nossas atitudes são ainda exemplos de conduta para uma parcela significativa da população, principalmente para as crianças e adolescentes, assim como são as de seus pais e seus professores. A nossa intervenção, enquanto médicos e coordenadores de equipes interdisciplinares, deveria começar por uma intensiva campanha de erradicação do vício entre os próprios profissionais da saúde. Entretanto, o maior obstáculo existente em nosso país é a influência do poder econômico da indústria do tabaco sobre as decisões políticas. Utilizando-se do argumento da necessidade de geração de renda e empregos, são vetadas muitas leis de controle da produção e comercialização do fumo no Brasil, sem se levar em conta todo o prejuízo financeiro e humano decorrente dessa atividade.

Felizmente, no Brasil, a prevenção das doenças crônicas do adulto desde a infância têm sido cada vez mais objeto de pesquisas muito bem desenhadas e conduzidas, ${ }^{8-10}$ de discussões acaloradas em salas lotadas dos nossos principais congressos médicos, de fóruns de secretarias municipais e estaduais, de capas de nossos principais jornais e revistas semanais ${ }^{11,12}$ e de grupos animados de discussões na internet ${ }^{13}$. De todas as regiões do Brasil têm vindo contribuições substanciosas para a sua melhor compreensão e para o controle de seus fatores de risco. Que se desenvolvam cada vez mais estudos sobre a prevenção das doenças crônicas desde a infância e a adolescência. Que a sociedade acorde sobre a importância da construção de hábitos saudáveis de vida desde a concepção, a forma mais barata e eficiente de prevenir esses males. E que o médico se sensibilize com a magnitude do problema e assuma seu papel como agente central nesse processo. Disso depende a mudança da história da saúde no Brasil.

Isabela Giuliano Senen Hauff 
Referências

I. Borio G. The tobacco history. tobacco org 2006 [cited 2006 Dec I0]. Available from: http://www.tobacco.org/History/Tobacco History.html.

2. Why is tobacco a public health priority? WHO 2006 [cited 2006 Dec I0]. Available from: http://www.who.int/tobacco/health priority/en/index.html.

3. INCA. Tabagismo. December I [citado 2006 dez. I 0]. Disponível em: http:/ /www.inca.gov.br/tabagismo/.

4). Giuliano IC, Coutinho MS, Freitas SF, Pires MM, Zunino JN, Ribeiro RQ. Lípides séricos em crianças e adolescentes de Florianopolis: Estudo Floripa 2040. Arq Bras Cardiol. 2005;85(2):85-91.

5. Horta BL, Victora CG, Menezes AM, Halpern R, Barros FC. Low birthweight, preterm births and intrauterine growth retardation in relation to maternal smoking. Paediatr Perinat Epidemiol. I997; I (2): | 40-5 I.

6. Ribeiro SA, Furuyama T, Schenkman S, Jardim JR. Atopy, passive smoking, respiratory infections and asthma among children from kindergarten and elementary school. Sao Paulo Med J. 2002; I 20(4): I09- I2.

7. Cigarros. ONG mensagem subliminar 2006 [citado 2006 dez. I0]. Disponível em: http://www.mensagemsubliminar.com.br/conteudo.php?id = LTQyNzcuMzU =
8. De MD, Formigoni ML. Drug use by Brazilian students: associations with family, psychosocial, health, demographic and behavioral characteristics. Addiction. 2004;99(5):570-8.

9. Galduroz JC, Noto AR, Nappo SA, Carlini EA. Trends in drug use among students in Brazil: analysis of four surveys in 1987, 1989, 1993 and 1997. Braz J Med Biol Res. 2004;37(4):523-31.

10. Galduroz JC, Noto AR, Nappo SA, Carlini EA. Household survey on drug abuse in Brazil: study involving the 107 major cities of the country200 I. Addict Behav. 2005;30(3):545-56.

| |. Bergamo G. O Bê-a-bá do coração saudável. Veja.2005; | 932:98-9. 23 nov. 2005.

I 2. Tarantino M, Castellón L. Coração para toda a vida. Isto É. 2005; I 884:4450. 23 nov. 2005.

1 3. Amigos do peito das crianças. [citado 2006 out.]. Disponível em: http:/ /br.groups.yahoo.com/group/amigosdopeitodascriancas./

14. Guedes DP, Guedes JERP, Barbosa DS, Oliveira JA. Uso de tabaco e perfil lipídico-lipoprotéico plasmático em adolescentes. Rev Assoc Med Bras. 2007; 53(I). 